\title{
A Global Energy Management System to Support Sustainable Decision Making ${ }^{+}$
}

\author{
Letizia D'Angelo ${ }^{1,2, *}$, Noel Finnerty ${ }^{3}$, Federico Seri ${ }^{1,2}$, Alessandro Piccinini ${ }^{1,2}$, Ronan Coffey ${ }^{3}$, \\ Carlos Tighe ${ }^{4}$, PJ Mealy ${ }^{4}$, Marc Mellotte ${ }^{4}$ and Marcus Keane ${ }^{1,2}$ \\ 1 Informatics Research Unit for Sustainable Engineering (IRUSE), Galway H91 TK33, Ireland \\ 2 College of Engineering and Informatics, Ryan Institute, National University of Ireland, \\ Galway H91 TK33, Ireland \\ 3 Boston Scientific Corporation, Ballybrit Business Park, Galway H91 Y868, Ireland \\ 4 Insight, Centre for Data Analytics, IDA Business Park, Lower Dangan, Galway H91 AEX4, Ireland \\ * Correspondence: letizia.dangelo@nuigalway.ie; Tel.: +39-3287734471 \\ + Presented at the Sustainable Places 2019 (SP 2019), Cagliari, Italy, 5-7 June 2019.
}

Published: 6 August 2019

\begin{abstract}
Global energy consumption has risen enormously over the past century due to population growth and increasing energy use per person. Industrial production consumes a significant portion of global energy resources. Thus, industrial sector's investment in energy efficiency is critical to a sustainable future. For most global enterprises the consumption of energy and natural resources represents a major overhead and developing sustainable energy policies can represent a significant competitive advantage due to the growing price of energy and volatility of supply. This symbiotic relationship can lead to the mutual benefits of increasing industrial efficiency whilst allowing the transition to a sustainable renewables-based energy future and needs to be significantly harnessed. This paper describes a decision support framework to help industrial organisations make positive investment decisions on energy performance improvement projects.
\end{abstract}

Keywords: global energy management system; corporate social responsibility; business continuity; sustainability; decision support framework; energy management maturity model; energy performance indicators

\section{Introduction}

Our planet is experiencing significant and accelerated climate change that began over a century ago [1]. With the increase use of fossil fuels, the worlds most diffused total primary energy supply, started with the Industrial Revolution, the level of greenhouse gases in the atmosphere have been increased from $280 \mathrm{ppm}$ (parts per million) to $430 \mathrm{ppm}$. It has been demonstrated [2] that the combustion of this energy source generates between $60-70 \%$ of the total global $\mathrm{CO}_{2}$ emissions. $\mathrm{CO}_{2}$ is classified as a greenhouse gas and, while $\mathrm{CO}_{2}$ is not the only greenhouse gas contributing to the problem, it is the most abundant greenhouse gas produced by human activities [3].

The manufacturing sector alone accounts for more than $98 \%$ of direct industrial green-house gas emissions [4] and $36 \%$ of total industrial $\mathrm{CO}_{2}$ emissions. [5].

Hence, given the direct relationship between GHG's and global warming [6], the progress made by the manufacturing industry in environmental sustainability merits industrial and academic focus. Climate change will have wide-ranging effects on the environment, and on socio-economic and related sectors, including water resources, agriculture and food security, human health, terrestrial ecosystems and biodiversity and coastal zones [7]. 
The most effective way for industry to achieve carbon emissions reduction, is through the implementation of Energy Management (EM), Energy Management Systems (EnMS) and ultimately Energy Efficiency Measures (EEM) [8].

The main drivers for implementing EEM in the manufacturing industry are legislative compliance and financial gain. While, to efficiently implement EM into organisations, international standards such as the ISO 5000 [9], are required through the development of an energy policy and an associated energy strategy.

This paper will focus on improving the EM and EnMS associated with industrial manufacturing organisations with a view to reach optimal energy efficiency and associated capital spend on EEM across the organisation, whilst in parallel meeting commitments to sustainability goals. The methodology has been validated in several pilot cases of the Boston Scientific Corporation (BSC), a non-energy intensive multi-national manufacturing organisation (MMO) in the life sciences industry.

\section{GEMS Concept and Approach}

GEMS provides a novel framework to enable non-energy intensive MMO meet their energy goals whilst in parallel optimizing their energy efficiency performance and associated investments.

The GEMS approach is based on a Parthenon structure, the goal is strategically placed at the top of the Parthenon and represents the highest-level aspiration of the organisation. In our case, BSC has set several targets to achieve and, in particular, the carbon neutrality of manufacturing operations by 2030 as outlined in Figure 1.

The GEMS Parthenon is a very effective "tool" to capture and convey the essential components of a global energy management system covering many complex topics simultaneously. The Decision Support Framework (DSF) can be reached through the development of 4 cross functional pillars, acting in parallel, and 3 essential foundations, pre-requisite to the pillars.

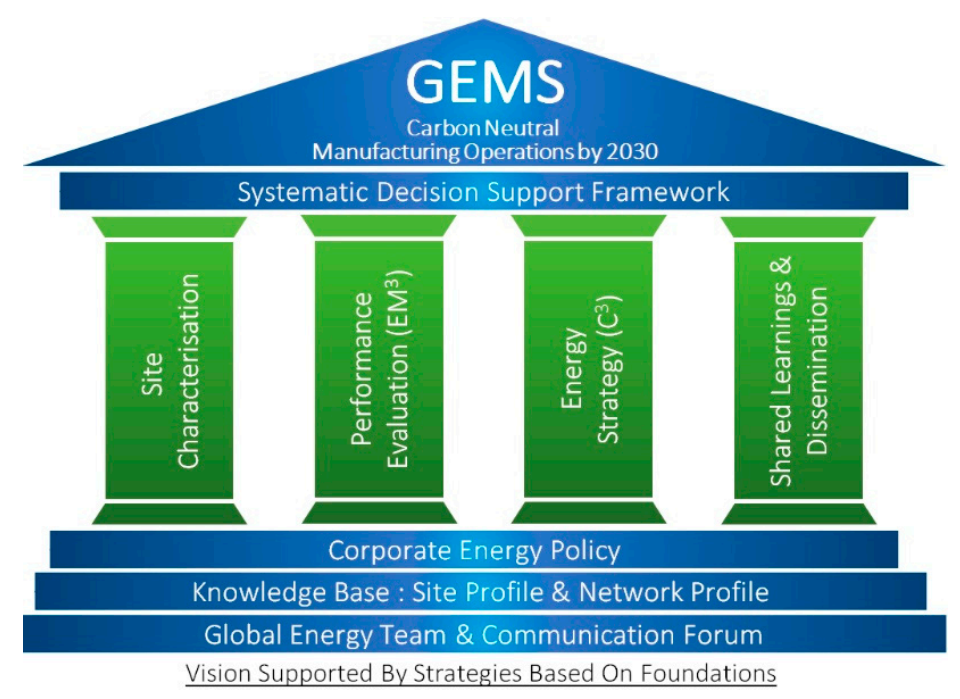

Figure 1. BSC GEMS Parthenon.

\subsection{Pillars}

\subsubsection{Site Characterisation}

Deploy a standards-based energy audit of each site in the network that represents the quantitative and qualitative energy management characteristics. A bespoke GEMS audit is carried out to establish the key quantifiable 'drivers' for energy consumption on each site. 


\subsubsection{Performance Evaluation:}

Aims at delivering a continuous benchmarking internally and externally, towards a continuous improvement cycle. It is conducted using a novel benchmarking approach by a combination of both quantitative key performance indicators (KPIs) and qualitative EM3 results

\subsubsection{Shared Learning and Dissemination}

Ensure the best methodologies and appropriate technological solutions across the network via a global communication forum.

\subsubsection{Energy Strategy}

The corporate energy strategy should define the targets, the roadmap and enablers required to meet the long-term goals that ultimately deliver the long-term vision committed by the 'corporate energy policy' foundation.

\subsection{Foundations}

\subsubsection{Global Energy Team and Communication Forum}

A global energy team and associated communication forum to ensure the individual site energy leads work effectively, enabling information sharing, performance tracking and relationship development.

\subsubsection{Knowledge Base at Site and Global Level}

Utilize a central platform for data collection, aggregation \& analysis.

\subsubsection{Corporate Energy Policy}

Part of the organisation's sustainability policy to improve environmental performance which in turns reflects the company's mission statement and core values.

\section{Pilot Demonstration}

The implementation of the methodology has started in 2013 with a pilot study in a single Irish site located in Galway. The pilot implementation consisted mainly of completing an onsite data gathering exercise (both qualitative and quantitative) and subsequent energy audit. Then the pilot implementation has been expanded to include more facilities in the same region (Cork and Clonmel) over the years, as shown in Figure 2.

All the locations had site level EnMs with varying levels of maturity, so the approach enabled continuous improvement via shared learnings as the pilot advanced, with increasing levels of complexity assessed regarding the variables that effect energy efficiency.

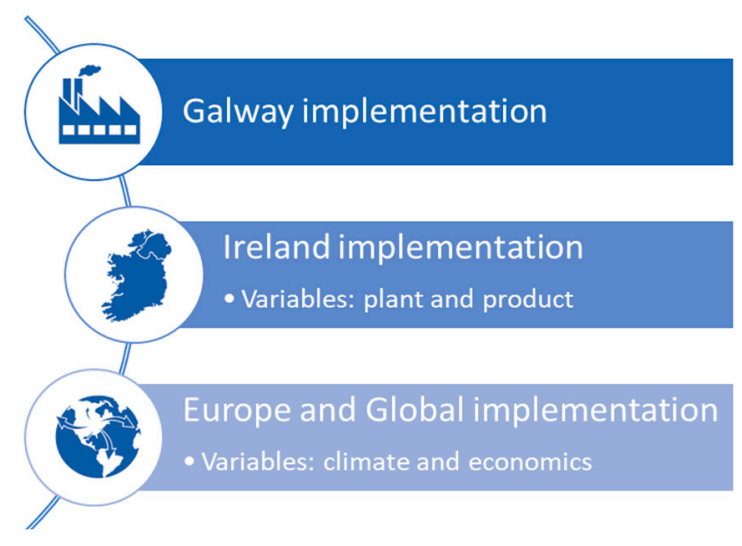

Figure 2. BSC GEMS Pilot-Implementation approach. 
A comprehensive table of energy saving opportunities and of the financial opportunity were compiled for each site in order to underline the opportunity that lies in GEMS audit implementation. Then, a GEMS multi criteria decision making analysis (MCDM) was applied to prioritise energy projects related to each BSC manufacturing plants using fuzzy logic to transform the linguistic responses from four experts within the organisation to a qualitative questionnaire designed to assess the relative importance they placed on each of the criteria.

\section{Conclusions}

For MMO, EM standards fail to provide clear indications of how to successfully implement EM, resulting in ad-hoc approaches typically used up to now. This leads to reduced environmental performance for MMO due to the lack of systematic approaches (e.g. decision-making processes) that efficiently articulate the organisation's efforts to become more environmentally sustainable. The methodology presented in this research work addresses this issue since it contains the key components of a long-term corporate energy policy and strategic roadmap to address the barriers and support the drivers in the implementation of EM and EnMS in MMO. The energy strategy helps reduce the gaps identified in the literature around decision making practices and the non-energy benefits.

Current best practice approach to global energy management suggests a siloed approach (site to site and corporate to site), where communication between sites is rare. The GEMS approach is innovative due to the structure of the management forum which enables an open communication flow between the sites and global and from site to site. The approach also critically has an embedded feedback loop which further fosters efficiencies through shared learning's between sites.

\section{Future Work}

The GEMS methodology will continue to be developed. The future work will include:

- Corporate level metering plan to support the KPI's.

- A bespoke matrix of technology solutions that will be developed for the corporation appropriate to its geographical locations.

- Development of standardised templates for all sites to follow when requesting corporate funding for energy conservation projects.

- A strategy for rewards and recognition for both site and corporate-level personnel.

- Best in class techniques for internal and external communications.

- DSF automation and usability improvement.

- Further develop the 'Policy' foundation and the 'Energy Strategy' pillar methodologies.

- Development of 'GEMS Implementation Guidebook for Industry'.

Acknowledgments: This publication has emanated from research supported in part by a research grant from Science Foundation Ireland (SFI) under Grant Number SFI/12/RC/2289 through a TP agreement between the National University of Ireland, SFI Centre for Ireland's Big Data and Analytics Research, ZuTec Inc. Ltd, Boston Scientific Corporation and R2M Solution Srl.

Conflicts of Interest: The authors declare no conflict of interest.

\section{References}

1. Directorate-General for Climate Action (European Commission). Our Planet, Our Future-Fighting Climate Change Together; Publications Office of the European Union: Luxembourg, 2018.

2. International Energy Agency (IEA). World Energy Outlook 2015; International Energy Agency (IEA): Paris, France, 2015.

3. IPCC. Carbon Dioxide Capture and Storage; Metz, B., Davidson, O., de Coninck, H., Loos, M., Meyer, L., Eds.; Cambridge University Press: Cambridge, UK, 2005. 
4. Fischedick, M.; Roy, J.; Abdel-Aziz, A.; Acquaye, A.; Allwood, J.M.; Ceron, J.-P.; Geng, Y.; Kheshgi, H.; Lanza, A.; Perczyk, D.; et al. Industry. In: Climate Change 2014: Mitigation of Climate Change; Cambridge University Press: Cambridge, UK; New York, NY, USA, 2014.

5. Bunse, K.; Vodicka, M.; Schönsleben, P.; Brülhart, M.; Ernst, F.O. Integrating energy efficiency performance in production management-gap analysis between industrial needs and scientific literature. J. Clean. Prod. 2011, 19, 667-679.

6. IEA. World Energy Outlook 2016 (Executive Summary); International Energy Agency (IEA): Paris, France, 2016; pp. 1-8.

7. UNFCCC. Climate Change: Impacts, Vulnerabilities and Adaptation in Developing Countries; United Nations Framework Convention on Climate Change: Bonn, Germany, 2007.

8. Costa-Campi, M.T.; García-Quevedo, J.; Segarra, A. Energy efficiency determinants: An empirical analysis of Spanish innovative firms. Energy Policy 2015, 83, 229-239.

9. ISO. Energy Management Systems-Requirements with Guidance for Use; ISO 50001:2011; International Organization for Standardization: Geneva, Switzerland, 2011; p. 16.

(C) 2019 by the authors. Licensee MDPI, Basel, Switzerland. This article is an open access article distributed under the terms and conditions of the Creative Commons Attribution (CC BY) license (http://creativecommons.org/licenses/by/4.0/). 